\title{
The question of symptom lateralization in conversion disorder
}

\author{
Karin Roelofs $^{\mathrm{a}, *}$, Gérard W.B. Näring ${ }^{\mathrm{a}}$, Franny C. Moene ${ }^{\mathrm{b}}$, Cees A.L. Hoogduin ${ }^{\mathrm{a}}$ \\ ${ }^{a}$ Department of Clinical Psychology and Personality, University of Nijmegen, PO Box 9104, 6500 HE Nijmegen, The Netherlands \\ ${ }^{\mathrm{b}}$ Organization for Mental Health Care, De Grote Rivieren, Dordrecht, The Netherlands
}

\begin{abstract}
Objective: The purpose of this study was to determine whether or not conversion symptoms are lateralized. Studies have shown a predominant left-oriented manifestation of symptoms for most somatoform disorders. The reports in the literature on the lateralization of conversion symptoms, however, are rather conflicting. They show left-sided, right-sided, or no symptom lateralization in conversion disorders. Methods: One hundred
\end{abstract}

fourteen patients with conversion disorder were screened for symptom lateralization. Results: Those patients with unilateral symptoms (32.5\%) showed no significant bias toward left or right symptom presentation. Conclusion: Based on these results, and the conflicting findings from previous studies, we conclude that there is insufficient support for lateralization theories in conversion disorder. (C) 2000 Elsevier Science Inc. All rights reserved.

\section{Introduction}

Are conversion symptoms lateralized? This question is often confronted in clinical practice and gave rise to numerous publications in the 1970s. A more recent publication by Min and Lee [1] has made it clear that a definitive answer is still lacking. Many studies show the symptoms of somatoform disorders other than conversion disorder to be mostly located on the left side of the body. This lateralization has been reported for pain symptoms [1-6] and hypochondriac symptoms [7]. The reports with regard to symptom lateralization in conversion disorders, however, are rather contradictory (for review, see Table 1). Left-sided lateralization of conversion symptoms has been found by Galin et al. [8] for females only, and by Pascuzzi [9] and by Stern [10]. Others have found a predominantly right-sided lateralization of conversion symptoms in both adults [11] and children and adolescents [12]. Three studies found no symptom lateralization in conversion disorder [13-15].

Three hypotheses have been put forth to explain the observed left-sided predominance of symptoms in somatoform disorder [2]. The hypotheses have been applied to

\footnotetext{
* Corresponding author. Tel.: +31-24-361-2153; fax:+31-24-3615594.

E-mail address: roelofs@psych.kun.nl (K. Roelofs).
}

conversion symptoms as well [10]. The so-called evaluative hypothesis suggests that negative connotations are associated with the left side of the body and that somatoform symptoms are therefore left-lateralized. Little empirical support has been found for this hypothesis, however. As part of the so-called convenience hypothesis, Stern [10] tested the possibility of symptoms developing on that side of the body where they produce the least inconvenience. The finding that both right- and lefthanded patients show the same predominance of left-sided conversion symptoms $[8,10]$, however, disproved this hypothesis as well. Yet another hypothesis explains the left lateralization of somatoform symptoms in terms of the functional asymmetry of the cerebral hemispheres and is often therefore referred to as hemispheric specialization theory. According to this theory, the right cerebral hemisphere is more involved in emotional reactions and thus mediates the manifestation of affectively determined somatic symptoms on the left side of the body [10]. Although the hemispheric specialization theory is the predominant theory at present, the mechanism by which the right cerebral hemisphere transforms negative emotions into somatic symptoms on the left side of the body remains unclear [16]. Recent findings from two brain mapping studies, one case of left-sided paraesthesia [17] and one case of left-sided conversion paralysis [18], have suggested the involvement of higher level cognitive, attention systems from the right hemisphere in conversion 
Table 1

Overview of studies examining lateralization of conversion symptoms ${ }^{\mathrm{b}}$

\begin{tabular}{|c|c|c|c|c|c|c|}
\hline Patient group & $\begin{array}{l}\text { Symptoms } \\
\text { studied }\end{array}$ & $\begin{array}{l}\text { Number of } \\
\text { patients: total } \\
(\mathrm{M} / \mathrm{F})\end{array}$ & $\begin{array}{l}\text { Percentage of } \\
\text { patients with } \\
\text { unilateral } \\
\text { symptoms }\end{array}$ & $\begin{array}{l}\text { Number of } \\
\text { patients with } \\
\text { left/right/both- } \\
\text { sided symptoms }\end{array}$ & $\begin{array}{l}\text { Conclusion } \\
\mathrm{L} / \mathrm{R} \\
\text { lateralization } \\
\text { (\% patients) }\end{array}$ & Reference \\
\hline $\begin{array}{l}\text { Patients evaluated by } \\
\text { neurology service (1986-1987) }\end{array}$ & $\begin{array}{l}\text { Unilateral } \\
\text { motor/sensory }\end{array}$ & $31(7 / 24)$ & - & $26 / 5 /-$ & $\mathrm{L}(84 \%)^{*}$ & Pascuzzi [9] \\
\hline \multirow[t]{3}{*}{ Hysterical neurosis, conv. type } & & $191(51 / 140)$ & & & & \\
\hline & Motor conv & $146^{\mathrm{a}}$ & $56 \%(81)^{\mathrm{a}}$ & $52 / 29 / 65^{\mathrm{a}}$ & $\mathrm{L}(64 \%)^{\mathrm{a}, *}$ & \\
\hline & Sensory conv & $155^{\mathrm{a}}$ & $74 \%(114)^{\mathrm{a}}$ & $78 / 36 / 41^{\mathrm{a}}$ & $\mathrm{L}(68 \%)^{\mathrm{a}, *}$ & Stern $[10]$ \\
\hline Psychiatric hospital patients & Conv. & $40(36 / 4)$ & $83 \%(33)$ & $8 / 25 / 7$ & $\mathrm{R}(76 \%)^{*}$ & Fallik and Sigal [11] \\
\hline $\begin{array}{l}\text { Child and adolescent in-patients } \\
\text { at psychiatric hospital }\end{array}$ & Conv. & $15(9 / 2)^{\mathrm{b}}$ & $73 \%(11)$ & $1 / 10 / 4$ & $\mathrm{R}(91 \%)^{* *}$ & Regan and LaBabera [12] \\
\hline $\begin{array}{l}\text { One or more of Engel's [25] } \\
\text { criteria of conv. disorder }\end{array}$ & $\begin{array}{l}\text { Unilateral } \\
\text { conv. }\end{array}$ & $22(11 / 11)$ & - & $12 / 10 /-$ & $\begin{array}{l}\mathrm{L}-\mathrm{R}: \mathrm{NS} \\
(\mathrm{L}: 55 \%)\end{array}$ & Bishop et al. [13] \\
\hline $\begin{array}{l}\text { Conv. disorder according to } \\
\text { Engel }[25]\end{array}$ & $\begin{array}{l}\text { Unilateral } \\
\text { conv. }\end{array}$ & $52(10 / 42)$ & - & $33 / 19 /-$ & $\begin{array}{l}\mathrm{L}-\mathrm{R}: \mathrm{NS} \\
(\mathrm{L}: 63 \%)^{\mathrm{c}}\end{array}$ & Galin et al. [8] \\
\hline Patients with hysterical disorders & Gait disorders & $60(23 / 37)$ & $7.8 \%(13)$ & $9 / 4 /-$ & $\begin{array}{l}\mathrm{L}-\mathrm{R}: \mathrm{NS} \\
(\mathrm{L}: 69 \%)\end{array}$ & Keane [14] \\
\hline $\begin{array}{l}\text { "Hysterical neurosis conv. type" } \\
\text { + conv. prior to DSM-II }\end{array}$ & Conv. & $\begin{array}{l}64(21 / 43) \\
205^{\mathrm{a}}\end{array}$ & $15 \%(31)^{\mathrm{a}}$ & $12 / 19 / ـ^{\mathrm{a}}$ & $\begin{array}{l}\mathrm{L}-\mathrm{R}: \mathrm{NS} \\
(\mathrm{R}: 61 \%)^{\mathrm{a}}\end{array}$ & Stefansson et al. [15] \\
\hline
\end{tabular}

Conv., conversion; L, left; R, right; NS, nonsignificant.

a The numbers refer to symptoms instead of patients.

b Gender was not identified for all participants.

c In the female sample, $71 \%$ showed left-lateralized symptoms $(p<0.01)$.

$* p<0.05$.

** $p<0.01$.

symptoms. Stern [10] and Sierra and Berrios [19] have attempted to explain left-sided symptom lateralization by drawing an analogy between anosognosia and the phenomenon of la belle indifférence in conversion disorder. Anosognosia is the denial of a (mostly left-localized) physical disorder associated with damage to the right parietal cortex and hypothesized to result from a failing attention function in the right hemisphere. As argued by Spence [16], however, this analogy is based on rather superficial phenomenological resemblances. Denying an organic impairment is not necessarily the same as going undisturbed by a psychogenic impairment, which is sometimes observed in conversion patients. Furthermore, pointing at the left hemispheric involvement in (equally lateralized) depressive symptomatology, Spence [16] criticized the simple localization of affect to one hemisphere.

As already pointed out, the reports on symptom lateralization in cases of conversion disorder have been less consistent and showed both left- and right-sided symptom lateralization. Additional hypotheses have therefore been developed to explain the predominantly rightsided localization sometimes observed in cases of conversion disorder [11,12].

The first hypothesis is more or less the opposite of the convenience hypothesis. According to the inconvenience hypothesis, the dominant limb is "chosen" because the resulting disorder will thereby offer greater inconvenience [11,12]. Studies have indeed shown $88 \%$ [10] and $100 \%$ [12] of patients with unilateral conver- sion symptoms to display their symptoms on their dominant (mostly right) side. This observation alone does not provide support for the causal relation suggested by the inconvenience hypothesis, however.

The second lateralization hypothesis predicts a relation between previous organic lesions and current conversion complaints. Fallik and Sigal [11], for example, found the conversion symptom to occur most often in the area or limb where a previous injury or organic defect has occurred $(65 \%$ of the 40 studied cases). They then suggested that conversion symptoms may more frequently appear on the dominant (mostly right) side of the body because injuries more frequently occur on the right side. A study by Axelrod et al. [2], however, showed no asymmetry in the bodily manifestation of organic damage.

In sum, the findings and theories on the lateralization of conversion symptoms are contradictory and tend to suggest either no, left-, or right-sided symptom lateralization. This fact alone demands further research. Furthermore, the aforementioned lateralization theories have found little empirical support for the proposed causal relations to date. Unfortunately, several of the preceding studies of the lateralization of conversion symptoms have also not been limited to cases of a full-blown conversion disorder $[9,11-14]$. Such heterogeneity prevents us from establishing whether conversion disorder is indeed an exception when compared with other somatoform disorders. In several studies $[8,10,13-15]$, moreover, systema- 
tic neurological screening was not performed for research purposes and the data on symptom lateralization were simply derived from the patients' medical charts.

In the present article, the results of a systematic investigation of symptom lateralization in 114 patients with conversion disorders according to the DSM-III-R [20] criteria are presented. The conflicting findings with regard to left- versus right-sided symptom lateralization in cases of conversion disorder, and the lack of empirical support for the causal relations put forth by the different lateralization theories, make the presence of symptom lateralization in conversion disorder questionable. We therefore hypothesized no significant symptom lateralization in cases of conversion disorder. Gender and handedness were also not expected to influence symptom lateralization in such cases.

\section{Method}

\section{Subjects}

Subjects included 114 patients with conversion disorder according to the DSM-III-R criteria. Between 1991 and 1998, the patients had applied for either in- or outpatient treatment at a general psychiatric hospital specializing in the treatment of conversion disorders and involved in a study of the treatment of conversion disorders [21]. The psychiatric screening was performed by a psychiatrist using the DSM-III-R criteria. A neurologist was responsible for the somatic screening, which was performed on all patients, even those who had previously undergone neurological examination. When necessary, more precise diagnostic techniques, such as serial computed tomography (CT) and brain scans or magnetic resonance imaging (MRI) were also undertaken. The neurologist referred the patient to a specialist clinic for further diagnostic procedures when appropriate. The diagnosis of conversion disorder was made by the psychiatrist on the basis of multidisciplinary findings. A total of 86 women and 28 men were studied, with a mean age of 38.0 years $(\mathrm{SD}=12.5$, range 17 to 67$)$ and 40.8 years $(\mathrm{SD}=10.2$, range 20 to 67$)$, respectively, and a mean duration for the conversion complaints of 49 months $(\mathrm{sD}=61.7$, range 1 to 324$)$ and 41 months $(\mathrm{SD}=47.7$, range 2 to 194), respectively. Of the 114 patients, 37 patients showed comorbidity on DSM-III-R Axis I. The following DSM-III-R criteria were met in (n) patients: depression (14); dissociative disorder NOS (13); dysthymic disorder (7); posttraumatic stress disorder (7); panic disorder (5); specific phobia (4); pain disorder (2); adjustment disorder (1); eating disorder (1); female sexual arousal disorder (1); unspecified mental disorder (1); dissociative amnesia (1); and generalized anxiety disorder (1). Note that patients could meet the criteria for more than one disorder.

\section{Procedure}

The data on symptom lateralization were collected during the psychiatric screening. The presence and location of the following conversion symptoms were systematically checked using a standard intake list: paralyses; pareses; contractures; tremors; bizarre movements; coordination disorders; speech disorders; eye muscle disorders; hearing disorders; vision disorders; feeling disorder; pain; and pseudoepileptic seizures. The patients were then identified as having unilateral conversion symptoms when the symptoms occurred on only one side of the body.

Data on hand preference were collected using Annett's Handedness Questionnaire [22]. This questionnaire and a return envelope were sent to the patients, and handedness was scored using the method described by Lishman and McMeekan [23].

The percentage of patients with unilateral symptom presentation was calculated, and the numbers of patients with unilateral versus bilateral symptoms were then compared using binomial testing. To test for a predominance of symptom presentation on one body half, the numbers of patients with only left-sided versus only right-sided symptoms were also compared using binomial testing. The effects of gender, handedness, and the presence of Axis I comorbidity on symptom side were estimated using Pearson's chi-square tests of independence in $2 \times$ 2 cross-tabulations. When the expected frequency for any of the cells was $<5$, Fisher's exact test was used. Furthermore, symptom duration was compared for patients with left-sided and right-sided symptoms using a $t$-test for independent samples.

\section{Results}

The incidence of the motor symptoms across patients was: paralyses $(n=19)$; pareses $(n=61)$; contractures $(n=17)$; tremors $(n=19)$; bizarre movements $(n=14)$; coordination disorders $(\mathrm{n}=39)$; speech disorders (aphonia and dysphonia) $(n=17)$; and eye muscle disorder $(n=9)$. As far as the sensory symptoms, 6 patients had vision disorders. Disturbed feeling $(\mathrm{n}=53)$ and pain $(\mathrm{n}=59)$ were observed in concurrence with motor disturbances. A total of 17 patients had pseudoepileptic seizures. Vision disorders and bizarre movements occurred only bilaterally, and bilateral body symptoms were observed during pseudoepileptic seizures. In the category of speech disorders, only aphonia with dysfunction for both vocal cords was observed. All other symptoms occurred both unilaterally and bilaterally.

Of the 114 patients, 77 (67.5\%) showed bilateral symptoms and 37 (32.5\%) showed unilateral symptoms. Bilateral symptom presentation occurred significantly more frequently than unilateral symptom presentation (two-tailed binomial test; probability $=0.5: p<0.001$ ). Of the 37 patients with unilateral symptoms, 23 showed left-lateralized symp- 
toms and 14 showed right-lateralized symptoms. This distribution was chance-based (two-tailed binomial test; probability $=0.5: p=0.19$ ). Of the 86 women in the study, 60 had bilateral symptoms, 18 had left-sided symptoms, and 8 had right-sided symptoms. Of the 28 men, 17 had bilateral symptoms, 5 had left-sided symptoms, and 6 had rightsided symptoms. There was no significant relation between gender (male, female) and symptom side (left, right) (twotailed Fisher's exact test: $\chi^{2}=1.86, p=0.27$ ).

A total of 80 patients $(70 \%)$ returned the handedness questionnaire. Of the 37 patients with unilateral symptoms, a total of 28 completed the handedness questionnaire. Of the 23 right-handed patients with unilateral symptom presentation, 15 had left-sided symptoms and 8 had right-sided symptoms. And, of the 5 left handed patients with unilateral symptoms, 4 had left-sided symptoms and 1 had right-sided symptoms. There was no significant relation between handedness (right, left/ambidextrous) and symptom lateralization (two-tailed Fisher's exact test: $\chi^{2}=0.41, p=1.0$ ). Furthermore, patients with left-sided symptoms did not significantly differ in symptom duration (months) (40.43, $\mathrm{SD}=45.0)$ from patients with left-sided symptoms $(36.70$, $\mathrm{SD}=39.20)[t(35)=0.27, p=0.79]$.

An overview of the total number of affected limbs per type of motor or sensory conversion symptom is shown in Table 2.

Table 2

Total number of motor and sensory symptoms in 101 patients with conversion disorder

\begin{tabular}{|c|c|c|c|}
\hline & Limbs & Left side & Right side \\
\hline \multicolumn{4}{|l|}{ Motor symptoms } \\
\hline \multirow[t]{2}{*}{ Paralysis } & Upper & 4 & 5 \\
\hline & Lower & 11 & 9 \\
\hline \multirow[t]{2}{*}{ Paresis } & Upper & 23 & 27 \\
\hline & Lower & 39 & 36 \\
\hline \multirow[t]{2}{*}{ Contractures } & Upper & 8 & 6 \\
\hline & Lower & 7 & 6 \\
\hline \multirow[t]{2}{*}{ Tremors } & Upper & 10 & 11 \\
\hline & Lower & 11 & 11 \\
\hline \multirow[t]{2}{*}{ Bizarre movements } & Upper & 9 & 9 \\
\hline & Lower & 5 & 5 \\
\hline \multirow[t]{2}{*}{ Coordination disorder } & Upper & 16 & 14 \\
\hline & Lower & 26 & 25 \\
\hline Eye muscle disorder & & 9 & 9 \\
\hline Total $^{\mathrm{a}}$ & & 178 & 173 \\
\hline \multicolumn{4}{|l|}{ Sensory symptoms } \\
\hline Hearing disorder & & 0 & 0 \\
\hline Vision disorder & & 6 & 6 \\
\hline \multirow[t]{2}{*}{ Feeling disorder } & Upper & 20 & 17 \\
\hline & Lower & 34 & 32 \\
\hline \multirow[t]{2}{*}{ Pain } & Upper & 24 & 22 \\
\hline & Lower & 34 & 21 \\
\hline Total $^{\mathrm{a}}$ & & 118 & 98 \\
\hline
\end{tabular}

The table excludes symptoms that are unlikely to show laterality and therefore excludes six patients with only a speech disorder and seven patients with only pseudoepileptic seizures.

a The number of left-sided vs. right-sided symptoms did not differ (two-tailed binomial test, probability $=0.5: p=1.0$ ).

\section{Discussion}

The objective of the present study was to determine whether patients with conversion disorder show symptom lateralization or not. A review of the relevant literature showed the previous findings to be rather conflicting: they show left-sided [8-10], right-sided [11,12], or no symptom lateralization [13-15]. The existing theories with regard to symptom lateralization were also found to lack empirical support. Our results are in agreement with the hypothesis that conversion disorder is not characterized by symptom lateralization. Most of the patients in the present study showed bilateral symptoms. Only $32.5 \%$ of the patients had lateralized symptoms and, within the subgroup of patients with unilateral conversion symptoms, a chancebased left-right distribution was found.

The lateralization rates reported in other studies of the lateralization of conversion symptoms vary between $83 \%$ [11] and 7.8\% [14]. This extreme variability may be due to certain methodological differences. In some studies [11,15], it was not made clear how symptom lateralization was defined. A patient with bilateral symptom presentation but a difference between the body sides with regard to the number and/or severity of symptoms may be assigned to the group of patients with symptom lateralization, for example. Such categorization is likely to inflate lateralization rates, however. Furthermore, the relatively high lateralization rate of $73 \%$ observed by Regan and LaBabera [12] was based on a small sample of children and adolescents $(\mathrm{N}=15)$. This makes generalization of the findings to the adult population questionable. Given these methodological differences, the lateralization rates across studies are difficult to compare.

Another finding of the present study was that no specific subgroups of patients with symptom lateralization could be identified. Neither gender nor handedness showed a significant effect on symptom lateralization. Lateralization also did not differ for symptom duration and symptom type (sensory, motor).

In order to localize conversion disorder in the brain, a parallel with the neurological syndrome of anosognosia has been made by some investigators $[10,19]$. Considering the broad manifestation of conversion symptoms, which covers the entire range of neurological symptoms, this analog does not appear to be very valid. Frequently occurring symptoms, such as tremors, unwilled excessive movement, or coordination problems are, for example, more reminiscent of neurological disorders, such as hyperkinesia, Huntington's disease, or Parkinson's disease than of hemineglect with anosognosia. The question that then arises is whether research should focus on localizing conversion disorder in one specific brain region. It may be more fruitful to study dysfunctional processes in the brain than to attempt to identify a specific "conversion" brain area [16]. One fruitful hypothesis emerging from recent neurophysiological studies suggests that higher cognitive processes, such as the atten- 
tional awareness system, may be involved in paralysis and paraesthesia (a subgroup of conversion disorder) $[17,18]$. Of special interest is the observation by Marshall et al. [18] of the involvement of the anterior cingulate cortex and the orbitofrontal cortex in conversion paralysis. Both brain structures have been identified as so-called negative motor areas that can inhibit spontaneous movement of the contralateral side [24]. Because these brain structures are bilaterally present, however, the implications for symptom lateralization are not at all clear.

Based on the following arguments, we conclude that there is insufficient support for the presence of lateralization in conversion symptoms: (1) the majority of conversion patients do not show symptom lateralization; (2) many conversion symptoms are unlikely to show lateralization (pseudoepileptic seizures, aphonia, excessive movements attacks); and (3) the studies that have found a significant lateralization of conversion symptoms showed conflicting findings with respect to left- versus right- lateralization.

\section{Acknowledgments}

The authors thank Pieter Sandijck and Muriel Hagenaars for their assistance during data collection and Paul Eling for his thoughtful comments.

\section{References}

[1] Min SK, Lee BO. Laterality in somatization. Psychosom Med 1997;59:236-40.

[2] Axelrod S, Noonan M, Atanacio B. On the laterality of psychogenic somatic symptoms. J Nerv Ment Dis 1980;168:517-25.

[3] Spear FG. Pain in psychiatric patients. J Psychosom Res 1967;11: 187-93.

[4] Halliday JL, The concept of psychosomatic rheumatism. Ann Int Med 1941;15:666-77.

[5] Edmonds EP, Psychosomatic non-articular rheumatism. Ann Rheum Dis 1947;6:36-49.

[6] Agnew DC, Merskey H. Words of chronic pain. Pain 1976;2:73-81.
[7] Kenyon FE, Hypochondriasis. A clinical study. Br J Psychiatry 1964;110:478-88.

[8] Galin D, Diamond R, Braff D. Lateralization of conversion symptoms. more frequent on the left. Am J Psychiatry 1977;134:578-80.

[9] Pascuzzi RM. Nonphysiological (functional) unilateral motor and sensory syndromes involve the left more than the right body. J Nerv Ment Dis 1994;182:118-20.

[10] Stern DB. Handedness and the lateral distribution of conversion reactions. J Nerv Ment Dis 1977;164:122-8.

[11] Fallik A, Sigal M. Hysteria, the choice of symptom site. A review of 40 cases of conversion hysteria. Psychother Psychosom 1971;19: $310-8$.

[12] Regan J, LaBabera J. Lateralization of conversion symptoms in children and adolescents. Am J Psychiatry 1984;141:1279-80.

[13] Bishop E, Mobley M, Farr W. Lateralization of conversion symptoms. Compreh Psychiatry 1978;19:393-6.

[14] Keane JR. Hysterical gait disorders. 60 cases. Neurology 1989;39: $586-9$.

[15] Stefansson JG, Messina JA, Meyerowitz S. Hysterical neurosis, conversion typeclinical and epidemiological considerations. Acta Psychiatrica Scand 1976;53:119-38.

[16] Spence SA. Hysterical paralyses as disorders of action. Cogn Neuropsychiatry 1999;4:203-26.

[17] Tiihonen J, Kuikka J, Viinamaki H, et. al. Altered cerebral bloodflow during hysterical paresthesia. Biol Psychiatry 1995;15:134-5.

[18] Marshall JC, Halligan PW, Fink GR, et. al. The functional anatomy of a hysterical paralysis. Cognition 1996;64:B1-B8.

[19] Sierra M, Berrios GE. Towards a neuropsychiatry of conversive hysteria. Cogn Neuropsychiatry 1999;4:267-87.

[20] American Psychiatric Association. Diagnostic and statistical manual of mental disorders, 3rd revised ed. Washington DC, American Psychiatric Association 1987.

[21] Moene FC, Hoogduin CAL, Van Dyck R. The inpatients treatment of patients suffering from (motor) conversion symptoms: a description of eight cases. Int J Clin Exp Hypnos 1998;XLVI:171-90.

[22] Annett M. Classification of hand preference by association analysis. Br J Psychiatry 1970;61:303-21.

[23] Lishman WA, McMeekan ERL. Hand preference patterns in psychiatric patients. Br J Psychiatry 1976;129:158-66.

[24] Lüders HO, Dinner DS, Morris HH, et al. Cortical electrical stimulation in humans. The negative motor areas. In: S Fahn, M Hallett, HO Lüders, et al. eds. Cortical electrical stimulation in humans. The negative motor areas, (Vol 67). Philadelphia: Lippincott 1995:115-29.

[25] Engel G. Conversion symptoms. In: MacBryde C.M., Blacklow R.S., editors. Signs and symptomsapplied pathologic physiology and clinical interpretation. 5th ed. Philadelphia: Lippincott, 1970. pp. $650-8$. 